\title{
The Ready-Made Pleasures of Déjà Vu: Repeat Viewing of Bollywood Films*
}

\author{
Arjun Appadurai
}

\begin{abstract}
This essay argues that the phenomenon of repeat viewing of films by Bollywood audiences is worthy of being treated as an unusual cultural practice in which repetition and difference support and reinforce each other in the manner suggested by Gilles Deleuze. This relationship is particularly enabled by the relationship of music to plot in these films, in which song sequences provide a repetitive or percussive element that deepens the melodic and innovative element provided by the story. Not all films are able to attract repeat viewers, which raises a question about the role of the "formula" in the Hindi film industry. Further, the pleasures of repetition in this domain offer a suggestive perspective on India's larger political dilemma, which is to combine the repetition of Western modernity with the unique developmental signature of Indian culture.
\end{abstract}

Keywords: repetition, difference, globalization, cinema, pleasure, Bollywood

\section{Repetition in Theory}

In theory-land, especially in the regions north and west of the Suez Canal, repetition has a bad reputation. Freud is probably the big culprit here, with his strong claims about repetition, obsession, and compulsion, though other Freudian ideas have recently been given higher exposure through Lacan, Zizek, and others. Still, Freud's negative views of repetition represent an old and complicated set of prejudices in the West, which have combined to give repetition a bad name. Repetition haunts the pages of Capital, and all of Marx's work is underwritten by the links between the repetitious nature of commodity-production (especially in the industrial regimes of the mid-nineteenth century) and other forms of alienation, exploitation, and

Arjun Appadurai is the Paulette Goddard Professor Media, Culture and Communication at New York University and is currently a visiting professor at Humboldt University (Berlin). He is the author of numerous books and essays on globalization, media, cities, and violence. His most recent book is Banking on Words: The Failure of Language in the Age of Derivative Finance (Chicago, IL: University of Chicago Press, 2016). (Email: aa133@nyu.edu)

* This paper has been more than two decades in the making and has had airings in Calcutta, New York, Toronto, Chandigarh, Berlin, and London, gathering wisdom from audiences in all these sites. The most recent occasion was at the British Academy in London, where I gained from the comments of participants at a panel to celebrate the conclusion of the ERC-funded project, Modern Moves, led by Ananya Jahanara Kabir. I am grateful for her comments as well as for those of two anonymous reviewers, who helped me to improve this paper. Ato Quayson also offered me some generous comments and encouraged me to publish this paper before it entered its third decade of incubation. 
dehumanization. Even deeper than these famous critiques of repetition lies the strong tendency, after the Renaissance, to associate originality, creativity, and authenticity with the idea of the virtuoso, the signature, and the artwork, thus banishing repetition (in the form of traditions of replication and imitation) to the margins of the work of the imagination.

Thus repetition has generally come to stand, in the post-Renaissance intellectual imaginary, for many bad things: imitation, fixation, alienation, habituation, and unfreedom. The idea of progress, so thoroughly iconic of the Enlightenment, has as one of its less noted others, the practices of repetition. In short, repetition today, even in the most sophisticated cultural criticism, is associated with the social and theoretical equivalent of autism, an endless practice without spirit, purpose, or future. Much twentieth-century criticism of mass consumption and the culture industries (notably inspired by the Frankfurt School) draws its energy from this suspicion, whose material face is the commodity and whose practical face is repetition, whether of consumption or production. Roland Barthes's lifelong antipathy to repetition is one famous example of this bias.

There are countercurrents to this view, of course, in such practices as music, military discipline, prayer, and some parts of avant garde art practice (think of Warhol's soup cans), but they make sense only as deviations from the dominant ideologies about repetition in which they are seen as a sign of some sort of failure of human agency and of some sort of deficiency in the social distribution of freedom. The major exception, which has emboldened me to pursue the intuition behind this paper, is Gilles Deleuze, whose major book on repetition and difference shows how these two ideas require and support each other and are wrongly seen as being in a relationship of antagonism or opposition. ${ }^{1}$

On the face of it, Deleuze's ideas about difference and repetition may seem remote from the experiences of ordinary fans of Hindi films in India. His difficult book is a manifesto that lays out Deleuze's metaphysics, and it seeks to address the most difficult issues in Western philosophy starting with the Greeks, those surrounding, identity, difference, and generality. Deleuze aligns himself firmly with Spinoza and Nietzsche, who insisted on linking being to becoming, and against Hegel, whose idea of dialectic, in Deleuze's view, always ends in a concept of being that is fixed, universal, and general. Deleuze inverts the historical relationship between identity and difference, in which difference is always based on some prior set of identities, but argues that "difference-in-itself" is not a difference between identities but rather a distinct and self-standing object that is the source of identity, rather than vice versa. This view leads Deleuze to argue that repetition is not the recurrence of the same experience at two different moments, but a repetition of difference, thus an always becoming, a new experience that does not rely on sameness, just as difference does not presuppose identity.

Thus, for Deleuze, difference and repetition constitute the motor of a different sort of time, not time seen as a line or circle that rests on identity and sameness. These ideas lead Deleuze to build his own theory of time that owes a substantial debt to 
Nietzsche's idea of the eternal return, which for Deleuze is not a return to a selfidentical time but a succession of moments of repetition-as-difference.

Because Deleuze's main aim was to respect experience and offer an immanent critique of Western metaphysics, he allows us to see that the Hindi cinema-goer's pleasure in repeat viewings of films is not a simple pleasure in sameness but has everything to do with the relationship between repetition and difference. Thinking through Deleuze led me to see that what I needed was a way to relate the joys of repetition to the principle of difference in Bollywood film culture. I do not aim for (or claim here) any new insight into Deleuze. His ideas on repetition and difference are a sort of philosophical allegory for the argument about repeat viewing that I try to spell out in what follows.

The repeat viewing practices of Hindi film audiences pose a problem for the general bias against repetition. What are we to do with those practices in which repetition is closely associated with pleasure? The examples from popular culture and the arts, both traditional and new, both Western and non-Western, are many: recurrent motifs in oral narratives, devices of punctuation in poems and other sorts of texts, percussive structures in music, as well as elicitations of déjà vu and recall in all sorts of visual and oral forms. In another register, the power of many sorts of parades, pageants, and large-scale bodily performances has much to do with the pleasures of rhythm and repetition (of which marching to a drumbeat is possibly the simplest example), and both performers and viewers in these contexts apparently enjoy something deeply connected with repetition. Indeed the greatest story-telling performance traditions in India and elsewhere have much to do with this repetitious, percussive aesthetic. I shall return to this special sort of reception tradition shortly.

For now, suffice it to say that certain critical approaches to the study of mass mediation and popular culture have no useful way to deal with the pleasures of repetition. In this paper, I do not pretend to offer a full answer to this problem, but I will pose a way to ask the question by looking at a specific practice that is vital to Indian film going (especially in respect to Hindi commercial cinema): the practice of repeat viewings of films. This practice is related both as cause and as effect to the popularity of some films, notably to those that become, in retrospect, "hits." Because the search for hits is the lifeline of financial success for the Bollywood film industry, figuring out what repeat viewing is about is not simply of academic interest. It has everything to do with such key issues as the "formula," the "star," and the type of film ("social," "love," "action" etc.) that audiences favor.

\section{Film and Repetition}

My argument has its basis in an ongoing study of Hindi commercial film culture in Bombay, in which I have been engaged for the last two decades. ${ }^{2}$ But its claims are

2 My arguments in this paper are contextualized and framed in two other papers on Mumbai and cinema, though neither of them takes up the question of repeat viewing: Arjun Appadurai, "Cosmopolitanism from Below: Some Ethical Lessons from the Slums of Mumbai," in The Future as Cultural Fact: Essays on the Global Condition (London: Verso, 2013), 197-214; Peter van der Veer, ed., "The Cinematic Soteriology of Bollywood," in Handbook of Religion and the Asian City: Aspiration and Urbanization in the Twenty-First Century (Berkeley, CA: University of California Press, 2015), 403-14. 
intended to apply to mass cinema viewing in other parts of India as well, notably in South India, where large cinema industries also exist. Thus I refer sometimes to Bombay and to Hindi films in particular and sometimes more generally to Indian film. Although it is common knowledge that ordinary viewers of Bollywood films frequently see films more than once, not much has been made of this important empirical fact. Producers and financiers, of course, have taken much note of it and indeed generally believe that the production of a "hit" film in Bollywood generally means that many viewers will see the film between one and a dozen times. ${ }^{3}$

Repeat viewing is also a common part of the everyday parlance of film appreciation in Bombay, where people will often tell one another that they have seen a film ten or fifteen times. Although it is not always clear that these numerical claims are exactly accurate, they indicate an aesthetic in which repeat viewing is a sign of the committed connoisseur. It is part of a language of connoisseurship and appreciation.

The most important element of this popular language of connoisseurship is the much-discussed role of music-specifically of songs_-in Hindi films. It is hardly news that almost every Hindi commercial film is a musical, with between ten and fifteen songs (frequently embedded in elaboration "production" numbers) that shape the narrative flow and appear with only the slightest plot provocation. These songs have several important features. Written frequently by authors who were Urdu language poets and often migrants to Bombay from the North (often from the north Indian state of Uttar Pradesh), these songs still have roots in certain popular forms of North Indian poetry, notably the ghazal, which are highly developed and aestheticized verbal forms.

More important is the fact that these songs are a big part of the acoustic ecology of everyday life in cities and small towns throughout the country, and sometimes even in villages. Often played in radios with loudspeakers or on gramophones, they saturate the soundscape of cities such as Bombay. In the 1950s and 1960s, they were played daily in radio programs such as Vividh Bharati, and today they are played along with their visual sequences in a variety of TV programs, as well as through mobile phones, car radios, and other digital media. Further, especially in Bombay in the 1950s and 1960s, they became a crucial part of the repertoire of street-singers, often father-son or brother-sister teams who took the place of the "star" duets in the films. These streetsingers are now on the wane, as cassettes and television push them to the edges of the

3 Many observers of Hindi cinema have noticed the importance of repeat viewing, and there is considerable evidence that repeat viewing continues to be an important principle of viewer pleasure, even if there have been many technological changes created by cassettes, DVDs, television, and live streaming, as well as by changes in modes of screening, such as the large multiscreen theater complexes. In other words, both for viewers and for producers, repeat viewing remains crucial to Bollywood culture and is not confined to the golden period of Hindi cinema in the 1950s and 1960s. See Shakuntala Banaji, Reading "Bollywood": the Young Audience and Hindi Films (New York: Palgrave Macmillan, 2006); Sabrina Ciolfi, "Popular Hindi Cinema: Narrative Structure and Points of Continuity with Tradition," in ACME: Annali della Facolta di Lettere e Filsofia del'Universiti degli Studi di Milano, vol. LXV-I (2012); Shilpa Jamkhandikar, "Forget Online Serials, Eros' Streaming Unit Bets on Bollywood Movies," Reuters, August 14, 2018; Lakshmi Srinivas, House Full: Indian Cinema and the Active Audience (Chicago, IL: University of Chicago Press, 2016). Further, the two films that have proven to have remarkable repeat value, even to the present, are Dilwale Dulhaniyaan Le Jaayengein (1995) and Kabhi Khushi Kabhi Gham (2001), both made long after the golden 1950s and 1970s in Hindi cinema. These films will be discussed later in this paper. 
soundscape, and other forms of petty urban employment prove more reliable. At the same time, their place is now frequently taken by singers in restaurants and cabarets, frequently quite upscale, in which Western-style dining out is complemented by Indian song-and-dance fare, either bland or semi-pornographic. The mujra tradition, in many Indian cities, thus fades into the cabaret tradition or its upmarket equivalents. Although each of these phenomena is worthy of further remark, the key point here is that film songs have saturated the urban soundscape in Bombay and much of urban India at least since independence in 1947.

This saturation reinforces the power of the film component of popular recorded music, whether on CD or on new technologies like MP3. In earlier decades, film songs on long-playing records (LP) dominated the market in mechanically produced music, but now the relationship between recorded music and film has changed in many ways. The most important change is the growing amount of recorded music (notably in semi-classical forms such as the ghazal), which is independent of film. As far as film is concerned, however, songs still play an important role, and at least in some cases songs have been the stimulus or starting point for film scripts and concepts. In any case, even today, digital recordings play a vital role in amplifying the filmic soundscape and in creating a part of the loop between repeat viewing and sound experiences outside the cinema hall.

A new force for expanding the logic of repetition came from the advent of the VCR around the early 1980s. Although fears about VCRs and TV as forces that would destroy the power of film viewing in cinema halls have proved incorrect, what videocassette viewing has done has been to complicate the aesthetics of repetition because it has, for a certain segment of the viewership, divorced the pleasures of repetition from the sociality of the cinema hall. This sociality is an important feature of repetition. ${ }^{4}$

Anyone who has been to a popular Hindi film knows that a large amount of the leadership in any given audience signals its authority by indicating its command of both songs and script, largely by cheering when a certain "hit" song or song-anddance sequence is about to begin, by singing along on occasion, and by expressing various bodily signs of pleasure when key songs arrive. This anticipatory pleasure and mnemonic command, which is part of the folk aesthetics of the cinema, is closely tied to the collective and interactive nature of film going and cannot be separated from two other elements of popular reception, dialogue, and stars.

Key chunks of the script are popularly referred to as dialogue (the English word is a standard part of Bombay Hindi). Indian film viewers are connoisseurs of dialogue, and the sure sign of a hit is the memorization of key sequences of dialogue and such statements as "usne bahut achcha dialogue kiya hai." The first film to make a national impact in terms of dialogue sequences that became almost as important as the songs was Sholay [Embers] (1975), although the critical appreciation of dialogue has a much longer history. In street aesthetics, dialogue is all important and has a status that is substantially independent of plot. What dialogue does is to deepen the viewers' sensuous pleasure in cinematic words and to enhance the appreciation of characters who are, by definition, stars.

4 Srinivas, House Full. 
Here some important connections need to be made. Hindi films revolve around stars, and stars may be defined (perhaps universally) as actors who exceed their characters and indeed give them definition. This does not mean that Indian film viewers simply see their favorite stars on screen and do not recognize "acting": it is commonly said that $\mathrm{x}$ or $\mathrm{y}$ star did very good "work $[\mathrm{kam}]$ " in a particular film. Yet the pleasures of recognition when a star appears are also unmistakable, in the form of cheers and claps. In Bombay, of course, the star phenomenon is supported by a known sociology of studios and stars' residences and favored restaurants and hangouts. Ordinary people often see stars in the flesh, while they are of course omnipresent in billboards, magazines, and other forms. There is thus a visual ecology that magnifies stars and creates a vast network of images in which star status is amplified. Thus stars are linked to characters, and both are linked to dialogue.

Further, the history of Indian cinema is incomprehensible without the key institution of "playback" singers, the most famous of whom have become cultural icons: Lata Mangeshkar, Asha Bhonsle, Mukesh, Mohammed Rafi, and so on. More interesting still, in the heyday of nationalism and decolonization (the 1950s and 1960s), there were important associations between the biggest stars and the biggest "playback" singers, as in the famous linkage of Raj Kapoor and Mukesh. These playback singers were not anonymous, yet, in the context of film viewing, they are wholly submerged in the personae of the character/star, so that a sensual blur is created between the named voice, the known star, and the filmic character. These links among playback singer, star, and character are a hallmark of India's period of high modernism, which can be marked as the period from 1950 to about 1965 .

In the aesthetics of repetition, this complex triple merger was both articulated and reinforced as records, cassettes, and other forms of mechanical reproduction allowed separate strands of repetition and recollection to emerge in the form of collections of tapes and CDs devoted to particular playback singers, as well as in the sale of recordings of particularly memorable songs. In turn, actual repeat viewing as well as its associated forms of mechanical reproduction create highly articulated practices of nostalgia, notably in two forms: first, the increased traffic in collections of hit songs from the past, sometimes in the original recordings sometimes in the form of recordings by vocal clones of the original singers (who are a species of derivative singing star); second, in the form of singers in urban restaurants and cabarets who are partly distinguished by their ability to play and sing "old" hits and classics as well as newer ones. Thus the auditory history of Indian films, especially the songs, remains tied to its current products and experiences via these practices of nostalgia. Such practices also produce a culture of recollection, repetition, and collective knowledge that spans viewing generations differently than in other film and music cultures.

Thus songs and script have a special character and function in the formation of a hit. What they point to is a special set of links between the cinema and its wider sensory environment in which repetition is tied to recall and reproduction of special bits of dialogue and whole songs. In fact, hit songs may be defined as songs which by their success organize the entire rhythm of a specific filmic experience by creating a series of links that hold the film experience together against any incoherence or flatness in either character or plot. 
This characteristic of reproduction and recall was also supported by the publication and sale of small chapbooks during the 1950s and 1960s, in which the full text of film songs was replicated in its entirety so that it could be thoroughly memorized by anyone who could afford a small sum and could read. These chapbooks seem to have declined in popularity, but they have now been replaced by a host of websites that offer film clips, old films, song sequences, song lyrics, translations, and even karaoke versions of these songs. Nostalgia has thus been reinforced, and new forms of reproduction enhance the pleasures of repetition.

Thus it now seems plausible to argue that the pleasures of repetition in Indian film viewing are closely tied to those of re-cognition, re-call, and re-turn. In this regard, popular films probably most closely draw on and resemble traditional forms of public religious narration and performance in India, which were tied up with complex forms of pleasurable re-cognition and repetition. Stories in traditional India, especially the best-known folk and classical ones, are always heard and enjoyed as if for the second time. ${ }^{5}$

This observation was my first break in my two decades of puzzling over the repeat viewing of Hindi films. It is at the heart of a potentially deep approach to the pleasures of repetition in film viewing because it draws our attention to the social relations of repetition, which blur the line between those who already know the song or script sequence in these forms and those who can join the community of viewers as if they are also seeing things for the second (or third, or fourth, or fifth) time. Put another way, insofar as a popular film succeeds in becoming a hit, by drawing repeat viewers as well as large numbers of viewers, it does so by achieving making every viewer feel the pleasure of the sense of seeing or hearing something for the second time, even when they actually see and hear it for the first time.

This then is the core of my hypothesis about the pleasures of repeat viewing in Indian commercial cinema: the films that attract repeat viewing do not do so because they most successfully manipulate the elements of the "formula." This latter theory is the major folk theory both of those within the industry and of ordinary viewers. But there is considerable reason to suspect that it is the sensation of always (and already) seeing a film again (i.e., for the second or more time) that actually produces the motivation to actually see it again. This paradox opens up a deep question about the aesthetics of popular cinema: namely, which films succeed (and why) in creating this experience of repetition even in the first viewing?

\section{Deleuze in Bollywood}

Let me now bring Deleuze back in again, having earlier stated that his views of the relationship between repetition and difference had enriched my own understanding of repeat viewing of Indian films. The sensation of seeing a film for the second time (even when the viewer is seeing it for the first time) is thus, exactly as Deleuze may have predicted, an experience of the repetition of difference, and not a repetition of the

5 I owe this insight to one of my teachers at the University of Chicago, the late A. K. Ramanujan, poet, translator, and cultural critic who observed that no one in India hears a story from the great Indian epics "for the first time." 
same. Put another way, the sense of a second viewing rests on both a difference from the imagined first viewing and a repetition of that imagined viewing. And because the first viewing is imagined, it can never be the same as the actual second viewing. Furthermore, this experience of repetition as difference lays the ground for more viewings, a Nietzschean eternal return, which is not a cyclical return to the identical original but a repetition of differences without a necessary end. ${ }^{6}$

With this Deleuzian understanding of difference, let us deepen our understanding of "formula" films (in Bollywood and perhaps in any commercialized cinematic culture) because the formula itself (as every producer knows) is no guarantee of avoiding a flop. Like any recipe, no formula is a guarantee against complete failure. The challenge is to manipulate the formula so as to create a new experience of viewing pleasure while calling forth the sense of repetition. Simple imitation of a prior hit rarely does the trick, as both audiences and filmmakers know very well. What is required is the peculiar and dynamic configuration of key elements (star, songs, production numbers, dialogue, and story are the key ones) that bring out the sensation of déjà vu all over again (as the old joke goes) without seeming simply imitative or mechanically replicative of some specific prior formula film. Thus the aesthetics of pleasure in repetition cannot be reduced, mechanically, to the pleasures of the formula because the formula is itself no mechanical guarantee of success.

Thus I would further argue that the pleasures of repetition are better viewed as partly involving percussion, namely a background of rhythmic repetition that supports melodic variation or innovation. In the context of Hindi film, the musical sequences, made up of numerous songs set within a musical theme that is repeated in the score, provide the element of rhythm or repetition, whereas the story line and script/dialogue provide the possibilities of improvisation and innovation. How does this dual structure relate to the pleasure of seeing a film for the first time but experiencing it as if for the second or even the third time? A possible approach to an answer lies in the idea of percussion. It is the song sequences in any film that provide the percussive element that recalls prior experiences of cinematic pleasure: of déjà vu, of seeing something one has seen before. But this percussive musical element needs to be successfully tied to the improvisatory element provided by story, script, and dialogue. Without this latter element, the film might seem like a mere repetition, imitation, or replica, in effect a fake. On the other hand, improvisation and novelty alone through narrative and dialogue can be interesting without being pleasurable, in the mode that revisitation, review, recall, and repeat alone can produce. When these elements work together, a Hindi film succeeds in exemplifying what Deleuze, in the philosophical argument with which I began, tried to describe as the inner relationship between repetition and difference. This dual structure is what hit films succeed in extracting from the set formula of stars, script, and song that every Hindi filmmaker knows so well. I exemplify this argument with a brief look at the two hit films I referred to earlier,

6 Here I must thank Ato Quayson for suggesting an interesting idea, namely that the films that produce the sensation of déjà vu are those that somehow contain, embryonically, the potential for repeat viewing, an element that viewers recognize and value. The difficulty with this suggestion is that it only defers the question of what this embryonic element might be and, more importantly, that it remains limited by the idea of some sort of identity between the viewed version and the (prior) imagined version, a view of the problem of difference and repetition that I think is inadequate. 
Dilwale Dulhaniyaan Le Jaayenge [The Brave Hearted Will Take the Bride] (DDLJ, 1995) and Kabhi Khushi Kabhi Gham [Sometimes There's Happiness, Sometime There's Sorrow] (2001).

These two films continue to stand out today as among the biggest box office hits of Bollywood history, the biggest profit-makers, the most watched (by repeat viewers as well as new viewers), the most listened to (in terms of their most important sings), and the most beloved by the association between their stars, Shah Rukh Khan and Kajol, whose screen chemistry is the key to both films. Much has been written about both these films, and I will not repeat the details.

There is widespread agreement that DDLJ changed the very shape of Hindi cinema and brought the overseas Indian audience as never before into the imagination of Bollywood filmmakers. There is also widespread agreement that these films are the very apex of Shah Rukh Khan's stardom: in the case of DDLJ, he himself characterized his career in terms of his role in this film. In both cases, the music composers were the brothers Jatin and Lalit Pandit. Finally, numerous reviewers have pointed out that these films manage to please older, more traditional viewers by romanticizing Hindu family values and younger viewers by promoting love, adventure, romance, and mobility.

It is possible to argue that the key to the enormous and durable success of the two films is the chemistry between the two aforementioned most beloved stars of Bollywood in the last two decades: Shah Rukh Khan and Kajol. It is also possible to argue that these films succeeded remarkably by making the Indian diasporic experience part of the mobile imaginaries of Indians in India. It is even possible that the outsize success of these films is due to the fact that they hit the spot on every key element from the Bollywood point of view: songs, dance sequences, story, stars, exotic locations, and design. There is something to each of these arguments. But none of them quite catches the relationship between repetition and difference that I have argued lies at the core of repeat value in Bollywood films.

I suggested earlier that the musical score (including songs, background music, and lyrics) of Bollywood hits provides the percussive element, the key to the pleasure of repetition, and that the plot (the narrative and the story) provides the element of difference and that it is the elusive balance between these elements that is the key to the Bollywood hit. Of course, there is no quantitative measure or algorithm for this blend, which is qualitative and experiential at its core. So we must abandon the effort to pin the balance down in any particular example. But we can certainly observe how these two elements come together in these two giant hits, especially as elements (recall Deleuze) that support, invoke, and engage one another rather than being in a relationship of opposition, contradiction, or mutual subversion.

The music in both films has been widely read as crucial to their remarkable success. As regards $D D L J$, there is considerable evidence that the songs in the film, and especially the most widely disseminated and remembered ones, are percussive insofar as they recall and echo earlier classical hit songs from earlier Bollywood films. Here are some fascinating observations by one of the music directors for DDLJ (Lalit Pandit) that support my interpretation. ' In this 2014 interview, Lalit notes that one of the

7 Lalit Pandit, "Interview with Subhash Jha," Rediff, December 16, 2014. 
songs in DDLJ, "Ruka Jaa O Dil Deewana [Wait, The One Who Makes My Heart Crazy] was composed in response to a request from the director, Aditya Chopra, that the song should be "like" the song "Bachna Ae Haseenon [Save Yourselves, Ladies] from the 1977 hit film Hum Kisise Kum Nahin [I Am Not Less Than Anybody] but that it should be in the style of a different star (Shammi Kapoor) than the star of the 1977 film, Rishi Kapoor (who is in fact the nephew of the late Shammi Kapoor). Likewise, for another hit song from $D D L J$, "Mere Khwabon me Jo Aaye [The One Who Comes in My Dreams] Aditya Chopra gave them a model in the hit song "Bhai Batur [Dear Friend]" from the 1968 film Padosan [Neighbor]. For the hit song, "Ghar Aaja Pardesi [Come Home Foreigner]" (a particular favorite for overseas Indian audiences), the director asked the lyricist Anand Bakshi to work from the model of an earlier song called "Chitthi Aayi Hai [A Letter Has Come Home]" from a 1986 film called Naam [Name]. In each case the idea was to repeat with a difference, thus suggesting that the use of film songs to produce a particular sense of déjà vu is not just an accident of the viewer/listener's archive but also a deliberate intention of the filmmaker.

In the 2001 superhit Kabhi Khushi Kabhi Gham, we can see a similar logic of music as percussion at play. ${ }^{8}$ The stars here are also Shah Rukh Khan and Kajol, but they are surrounded by other stars (Amitabh Bachchan, Hritik Roshan, Rani Mukherji) and the filmmaker is Karan Johar, one of the superstars of production and directing in Bollywood since the mid-1990s. The songs in this film did not have quite the massive following as the songs in $D D L H$, but they were a key part of its runway success. This film also employs repetition as difference in respect to an earlier hit film, also by Karan Johar, called Kuch Kuch Hota Hai [Something Is Happening] (KKKG, 1998), both in regard to songs and in regard to story line. It also echoes aspects of two other hit films by Aditya Johar, DDLJ (discussed already) and Mohabbattein [Love of a Lifetime] (2000) and has songs that echo but do not mimic songs from such earlier films as Pukar [Crying Out] (2000). Thus the two hits we have discussed briefly, $D D L J$ and $K K K G$, belong to a closely linked set of movies (especially their songs and lyrics) from 1995 to 2001, but they also hark back to earlier hit songs and films, going at least as far back as 1968. This suggests that Hindi filmmakers as well as Hindi film viewers have a rich sonic and visual archive on which they rely and they commonly seek pleasure through repetition as difference.

In both these films, furthermore, the plot does move the viewing experience forward, whether in terms of themes (such as the importance of designer lifestyles and overseas travel) or locations (increasingly cosmopolitan, not just exotic) or social aspirations (career, consumption, display). But in regard to plot, as well, it is not mere newness that is valued, but newness in repetition, with themes of love, family, friendship, loss, and marriage always present. Thus we might say that both music and plot in these films share the burden of finding repetition in-difference, though plot emphasizes difference and music the burden of repetition. In both cases, the common effect is might be called re-cognition.

8 Sukanya Verma, "Hate It, Love It: You Simply Can't Ignore the Tunes of Kabhi Khushi Kabhi Gham," Rediff, October 16, 2001. 


\section{Repetition as a Postcolonial Experience}

The pleasures of repeat viewing have as their larger environment a postcolonial society that has been independent since 1947 and was constructed itself as a modern, secular, scientific, and dynamic society. As with many postcolonial nation-states, the hopes of prosperity, peace, justice, and inclusion, all enshrined in the Indian constitution in various ways, have not been realized for the vast majority of its population. The aspiration socialism and secularism of the period of Jawaharlal Nehru has been substantially replaced by a strange combination of Hindu nationalism, global economic ambitions, and rampant anti-intellectualism. On the ground and in the streets, violence against women, lower castes, Muslims, as well as students, journalists, and activists has become an open part of the public sphere and takes the form of lynching, rape, and shootings, encased in an ideological aspic composed of bloodthirsty religious nationalism, fear of art and ideas, hatred of minorities, and a cult of the ruling party and the prime minister, Narendra Modi.

The burden of repetition has underwritten the logic of modernization/development in the project of the Indian nation-state since the 1950s, 1960s, and 1970s, when the ruling anxiety was the desire to enter the present of the West and to move away from India, defined as the seat and site of the past as habit, nature, and tradition. This anxiety was companied by a massive series of plans and policies to modernize Indian agriculture, build science and technology, and promote Western education and infrastructure in the name of national development. The anxiety was to escape from the treadmill of eternal behindness, and what this led to was a constant struggle to catch-up with the West in every area of life from sanitation to nuclear power. The decades of the 1950s and 1960s and to some extent the 1970s were India's socialist moment, where the commitment to end poverty, realize social justice, and promote equality were serious goals, even if the results were far from convincing. Repeating the history of the industrial West, without every catching up, seemed to be the destiny of India.

This unspoken anxiety undergirded a vast proportion of the critiques of modernity (from both ends of the political spectrum) in India in the Nehurvian decades, for it reflected the sense that modernity is above all an endless game of catch-up whose key technique is repetition (and its attendant practices of mimicry, flattery, dependence, inauthenticity, and the like). This anxiety also underlay much debate about culture and cultural policy leading to endless permutations of the effort to be "Indian" in some or other way while seeking to catch up with the already past history of the West. This anxiety is very much an elite preoccupation at least as old as the underlying rhetorical obsession of Nehru's The Discovery of India (1946), ${ }^{9}$ whose every page is driven by the search for India's essence or cultural genius.

The period since the mid-1980s witnessed the transformation of this anxiety about repetition into one about replication and standardization in the era of globalization. Even before the fall of the Berlin Wall in 1989, Indian elites had begun to tire of the promises of industrialized socialism and were moving to a greater interest in emerging technologies, global markets, and foreign investment as the solution to India's problems. In India, also earlier than much of the rest of the world, one can 
detect the uncanny co-emergence of global neoliberalism and religious or cultural nationalism. In 1991, Indian right-wing forces smashed a major Muslim mosque, the Babri Masjid, in the north Indian city of Ayodhya, claiming it was originally a Hindu shrine. This act of cultural vandalism had been prepared for several years by an alliance of Hindu revivalist politicians, holy men, and hooligans, and it led to armed reactions among Muslims in many Indian cities, which in turn led to the most massive Hindu violence against Muslim populations since the partition of Indian in 1947. In retrospect, the events of December 1991 and January 1992 were the opening act in the rise of the Bharatiya Janata Party (BJP), the major Hindu nationalist party to power, a fact that was nationally realized in the general elections of 2014, in which Narendra Modi, the political leader of the BJP, became the prime minister of India. In the two decades between the destruction of the Babri Masjid and today, what we have witnessed is the increasing impunity with which the Hindu right has grabbed political power, silenced opponents, crushed dissent, muzzled the media, and promoted a cult of its leader. At the same time, Modi and his supporters paint themselves as friends of free markets, global competition, aggressive financial policies, and forceful global diplomacy. Modi's India is no longer about catching up through repetition. It is about the coeval replication of the "best practices" of globalization, about making India a contemporary hub, an Asian version of the bastions of global power across the planet. Globalization abroad, cultural repression at home: this is the formula of the new order.

Indian film viewers, who are typically not members of this elite, had, and continue to have, a different purchase on modernity, which they view substantially as a space of glamour, of wealth, of style, and of pleasure. Put another way, they enter and experience modernity from a cultural point of view mainly through the practices of consumption and viewership, through what I some years ago called "the work of the imagination." ${ }^{10}$ It is of course easy, and common, to describe this popular take on modernity as escapist and anti-critical, and as grist for the mills of capital. But it is also an alternative way to understand, process, and debate the material of modernity and of domesticating, through song, script, character, and plot, the dynamics of wealth, beauty, glamor, and power.

I have proposed that in the repeat viewing of films, ordinary Indians derive pleasure from seeing films in their first viewing as if for the second time. In this sense, they recapture the experience of repetition as pleasure, not as discipline or as mimicry. Here then is-at the very least-a formal possibility for the mediation of modernity as pleasure rather than as discipline or as repression of dissent. Whether such practices of reception in popular mass media may harbor democratic potential in the era of globalization remains to be seen. Any observer of India today will have noticed Prime Minister Narendra Modi's open effort to dislodge the memories and institutions of Nehruvian modernism: its secularism, multiculturalism, and cosmopolitanism. Modi's vision of India is global and globalizing, and it seeks to bypass the problem of repetition by installing replication as its driving motif. Yet Modi too invokes the Indian (and especially the Hindu) past at every turn. He wants Hindutva to provide the rhythmic, percussive element that promises the joys of repetition, while his story line

10 Arjun Appadurai, Modernity at Large: Cultural Dimensions of Globalization (Minneapolis, MN: University of Minnesota Press, 1996). 
is about globalization, digital technology, and smart cities, in other words of a story line about innovation, competition, and global power for India. Will Modi succeed in his effort to make Hindutva the source of India's repeat pleasure while installing globalization as its narrative drive forward? The Owl of Minerva has yet to fly on this matter, but many of us are wagering on the possibility that Modi has not got the formula right and that perhaps very soon, Modi's vision of a Hindu India will prove to be a flop, not a hit. 